\title{
An NMR Metabolomics Approach and Detection of Ganoderma boninense-Infected Oil Palm Leaves Using MWCNT-Based Electrochemical Sensor
}

\author{
Azizul Isha $\mathbb{D}^{1},{ }^{1}$ Fowotade Sulayman Akanbi, ${ }^{2,3}$ Nor Azah Yusof $\mathbb{D}^{2,4}$ Rosiah Osman ${ }^{4},{ }^{4}$ \\ Wong Mui-Yun, ${ }^{5}$ and Siti Nor Akmar Abdullah ${ }^{5}$ \\ ${ }^{1}$ Laboratory of Natural Products, Institute of Bioscience, Universiti Putra Malaysia, 43400 UPM Serdang, Selangor, Malaysia \\ ${ }^{2}$ Department of Chemistry, Faculty of Science, Universiti Putra Malaysia, 43400 UPM Serdang Selangor, Malaysia \\ ${ }^{3}$ Department of Science Laboratory Technology, Hussaini Adamu Federal Polytechnic, A2 Kazaure, Nigeria \\ ${ }^{4}$ Functional Devices Laboratory, Institute of Advanced Technology, Universiti Putra Malaysia, 43400 UPM Serdang, \\ Selangor, Malaysia \\ ${ }^{5}$ Institute of Plantation Studies, Universiti Putra Malaysia, 43400 UPM Serdang, Selangor, Malaysia
}

Correspondence should be addressed to Azizul Isha; azizul_isha@upm.edu.my and Nor Azah Yusof; azahy@upm.edu.my

Received 17 January 2019; Revised 5 March 2019; Accepted 26 May 2019; Published 19 June 2019

Academic Editor: Andrew R. Barron

Copyright (C) 2019 Azizul Isha et al. This is an open access article distributed under the Creative Commons Attribution License, which permits unrestricted use, distribution, and reproduction in any medium, provided the original work is properly cited.

\begin{abstract}
Ganoderma boninense ( $G$. boninense) has been identified as a major problem in oil palm industry which caused basal stem rot disease. Identification of metabolite variation of healthy and G. boninense-infected oil palm leaves at 14 days postinfection using NMR metabolomics approach followed by characterization of an electrochemical sensor based on a functionalized multiwalled carbon nanotube (MWCNT) layer-by-layer framework on modified screen-printed carbon electrode has been successfully determined. Significant differences from the ${ }^{1} \mathrm{H}$ NMR data were observed between healthy and G. boninense-infected oil palm leaves, according to principal component analysis. Gold nanoparticle-functionalized MWCNT and chitosan-functionalized MWCNT were deposited on a screen-printed carbon electrode and were applied for the electrochemical detection of healthy and G. boninense-infected oil palm leaves. The electrocatalytic activities of a modified electrode towards oxidation of healthy and G. boninense-infected oil palm leaves at a concentration of $100 \mathrm{mg} / \mathrm{L}$ were evaluated using cyclic voltammetry and linear sweep voltammetry. The limits of detection of healthy and G. boninense-infected oil palm leaves were calculated to $0.0765 \mathrm{mg} / \mathrm{L}$ and $0.0414 \mathrm{mg} / \mathrm{L}$, respectively. The modified electrode shows a good sensitivity and reproducibility due to the unique characteristics of gold nanoparticles, chitosan, MWCNTs, and synergistic interaction between them.
\end{abstract}

\section{Introduction}

Basal stem rot is a major disease in oil palm industry which is caused by a soil-borne pathogen called Ganoderma boninense (G. boninense). This disease can cause direct loss of stand, reduced yield of diseased palms, and raised replant recurrence [1]. G. boninense infects oil palm at all stages, from seedlings to old plants through root to root contact. Infected young palms normally die within one or two years, whereas mature trees can survive up to three years [2]. Most of the affected trees die within six to 12 months after the sign of symptoms if not detected earlier, and some affected trees may live for several more years [3].

Despite G. boninense being apparently the main problem of the disease in oil palms, strategies and approaches for the early detection and control of G. boninense are still unfledged. A variety of studies on diagnostic methods has been applied to overcome the disease but is not sufficient to achieve satisfactory results. At the early stage of infection, the affected trees did not show any signs or symptoms which impose challenges in detecting the disease. The physical appearance of an initial infection symptom such as the 
existence of fungal mass or fruiting bodies, yellowing or browning of leaf, and stunted growth has been reported as early as two months after inoculation [4]. It has been suggested that the fungus may grow internally before the physical appearance of infection symptoms. Previous works done by other researchers have been reported on the identification of proteins of altered abundance in oil palm infected with $G$. boninense at 14 days postinfection using 2-dimensional gel electrophoresis [5]. Therefore, 14-day postinfection has been selected for the early detection of $G$. boninense in this study.

Application of ${ }^{1} \mathrm{H}$ NMR metabolomics approach in identifying metabolite variation of $G$. boninense-infected leaves has not been reported so far. Compared to other metabolomics platforms, NMR metabolomics platforms provide several benefits. ${ }^{1} \mathrm{H}-\mathrm{NMR}$ analysis is less complex as the sample does not need prior derivatization, extraction, and separation as required by mass spectrometry. In addition, ${ }^{1} \mathrm{H}$-NMR functions as an independent instrument compared to mass spectrometry which requires separation instrument like liquid chromatography or gas chromatography [6]. Thus, we applied a simple and reliable method, i.e., ${ }^{1} \mathrm{H}-\mathrm{NMR}$ analysis-based metabolomics for the identification of metabolite variations in G. boninense in oil palm leaves at an early stage, i.e., 14 days postinfection, and continued with an alternative electrochemical sensor.

The use of carbon nanotubes (CNTs) as a surface modifier of electrode has been increased in sensor technology. It provides several benefits such as excellent carrier mobility of a crystal lattice and lower thermal and electric noises. It also gives high mechanical strength, high thermal conduction, and optical properties which are possible to use in different type of sensors [7, 8]. Referring to the structural properties, carbon nanotubes provide high aspect ratios to adsorb chemical species. The selection of immobilization chemistry and functionalization of a carbon surface with a chemical or biomarker are crucial steps in the preparation of a transducer substrate. The transducer substrate should be resistant to degradation and allow maximal retained activity of receptor and transduction at the same time. Meanwhile, the transducer surface must adhere irreversible to the biosensor and could not interfere with the transduction signal [9].

Multiwalled carbon nanotubes (MWCNTs) are polymers of pure carbon which provides opportunity to modify the structure, optimize solubility and dispersion, and allow innovative applications in sensor. Due to the large specific surface area and the combination of strong $\pi-\pi$ interactions and hydrophobic interactions, the CNTs are capable to adsorb various chemical species such as aromatic compounds and natural organic matter [10-13]. To date, electrochemical MWCNT-based sensors have been applied widely in agriculture, food industry, occupational safety, medicine, and forensic chemistry. Liang et al. studied a carbon paste electrode modified by the poly(sulfosalicylic acid) and MWCNT composite for the detection of catechol [14]. Sadeghi and Gamroodi reported a screen-printed carbon electrode modified with quercetin/MWCNTs fabricated for the determination of $\mathrm{Cr}(\mathrm{VI})$ in the presence of the excess of $\mathrm{Cr}$ (III) without any pretreatment [15]. The two works above obtained high sensitivity and good anti-interference ability.
In this study, activated multiwalled carbon nanotubechitosan and activated multiwalled carbon nanotube(MWCNT-) gold nanoparticles (AuNPs) were developed to modify the surface of a disposable screen-printed carbon electrode (SPCE), applying a layer-by-layer (LBL) assembly method. The nanocomposites were produced by grafting the nanomaterials to the surface of the activated multiwalled carbon nanotube-chitosan (MWCNT-CTS). The modified electrode gave better sensing and provided a new option for constructing an effective electrochemical sensor for the determination of $G$. boninense-infected oil palm at 14 days postinfection.

\section{Materials and Methods}

2.1. Materials. All chemicals were used as received without further purification. Methanol, deuterated methanol- $\mathrm{d}_{4}$ $\left(\mathrm{CD}_{3} \mathrm{OD}, 99.8 \%\right)$, nondeuterated potassium dihydrogen phosphate $\left(\mathrm{KH}_{2} \mathrm{PO}_{4}, \mathrm{pH} 6.0\right)$, deuterium oxide $\left(\mathrm{D}_{2} \mathrm{O}\right.$, 99.9\%), and trimethylsilylpropionic acid- $\mathrm{d}_{4}$ sodium salt (TSP) were purchased from Merck (Darmstadt, Germany). Gold (III) chloride trihydrate ( $\geq 99.9 \%)$ and sodium citrate dehydrate $(\geq 99 \%)$ used for the synthesis of gold nanoparticles of different sizes, multiwalled carbon nanotubes $( \pm 90 \%$, $110-170 \mathrm{~nm}$ in diameter and 5-9 $\mu \mathrm{m}$ in length), and chitosan were all obtained from Sigma-Aldrich (St. Louis, USA). Iron (III) trioxonitrate (V) nonahydrate was purchased from Fluka (Durban, South Africa). Ethanol (99.8\%), methanol, and sulphuric acid (95-97\%) were bought from Friendemann Schmidt (Parkwood, Australia). Citrate buffer solutions (CBS) with a $\mathrm{pH}$ range of $3.0-6.2$ at $25^{\circ} \mathrm{C}$ were prepared by mixing stock solutions of $0.11 \mathrm{M}$ citric acid and $0.10 \mathrm{M}$ sodium citrate dehydrate, while adjusting the $\mathrm{pH}$ with $\mathrm{HCl}$ $(1.0 \mathrm{M})$ and $\mathrm{NaOH}(2.0 \mathrm{M})$ solutions.

2.2. Preparation of Rubber Wood Blocks for Artificial Inoculation. The rubber wood block (RWB) was prepared according to the method previously described [16]. Cultures of $G$. boninense PER 71 were obtained from the stock collection of the Department of Plant Protection, Faculty of Agriculture, Universiti Putra Malaysia. RWBs in a size of $6 \mathrm{~cm} \times 6 \mathrm{~cm} \times 6 \mathrm{~cm}$ were purchased from Wah Heng Rubber Wood Factory Sdn Bhd, Semenyih, Selangor. Small pieces of $G$. boninense-infected oil palm leaves which have been cut into $1 \mathrm{~cm} \times 1 \mathrm{~cm}$ were inoculated into the RWBs and incubated in the dark for 30 days until the blocks were fully colonized.

2.3. Plant Cultivation. Commercial DxP GH500 germinated seedlings which have been used as planting materials were bought from Sime Darby Seeds \& Agricultural Services Sdn Bhd, Banting. Five germinated seedlings were treated with $G$. boninense-inoculated RWBs whereas five germinated seedlings without any treatments of RWBs were used as a control. Treatment was performed for up to 14 days. Leaves samples were harvested at 14 days postinfection. Liquid nitrogen was used to quench each sample and ground into a powder form before being stored at $-80^{\circ} \mathrm{C}$. A freeze-dry 
system (Scanvac Labogene) was employed to remove the water content in the samples.

2.4. Sample Preparation. The freeze-dried leaves powder of healthy and $G$. boninense-infected oil palm (150 mg) was extracted by sonication in $80 \%$ methanol $\left(30 \mathrm{~min}, 40^{\circ} \mathrm{C}\right)$. The extraction step was repeated twice, and the total combined supernatant was filtered through a filter paper (Whatman, $125 \mathrm{~mm}$ ) and evaporated using a rotary evaporator. The crude extracts were then kept at $-80^{\circ} \mathrm{C}$ until analysis.

2.5. NMR Measurement and Multivariate Data Analysis. A $500 \mathrm{MHz}$ Varian INOVA NMR spectrometer (Varian Inc., Palo Alto, CA, USA), functioning at a frequency of $499.887 \mathrm{MHz}$ at room temperature $\left(25^{\circ} \mathrm{C}\right)$, was employed to determine ${ }^{1} \mathrm{H}-\mathrm{NMR}$ and $J$-resolved experiments. Samples were prepared according to the method previously described [17]. A $50 \mathrm{mg}$ sample was weighed in a $2.0 \mathrm{~mL}$ Eppendorf tube. A total of $0.75 \mathrm{~mL}$ of a $1: 1$ mixture of methanol- $\mathrm{d}_{4}$ and potassium dihydrogen phosphate buffer (pH 6.0) in deuterium oxide containing $0.1 \%$ trimethylsilylpropionic acid- $\mathrm{d}_{4}$ sodium salt was added. The mixture was vortexed ( $1 \mathrm{~min})$, ultrasonicated $(20 \mathrm{~min})$, and centrifuged $(10,000 \mathrm{rpm}, 10 \mathrm{~min})$ at room temperature. The supernatant $(0.6 \mathrm{~mL})$ was transferred to an NMR tube to run NMR analysis subjected to ${ }^{1} \mathrm{H}-\mathrm{NMR}$ measurement. A presaturation sequence was applied to eliminate the residual water signal. The resulting spectra were manually phased and baseline corrected using the Chenomx software (v.5.1, Alberta, Canada) with a consistent setting for all spectra. Spectral intensities were binned by equal width $\left(\begin{array}{ll}\delta & 0.04\end{array}\right)$ corresponding to the region of $\delta 0.50-$ 10.00. The regions of $\delta 4.70-4.90$ representing water and $\delta$ 3.23-3.36 representing residual methanol were excluded. A 2D J-resolved experiment was determined for additional support in the metabolite identification. Multivariate data analysis by principal component analysis (PCA) was performed with the SIMCA-P software (v. 13.0, Umetrics, Umeå, Sweden) using scaling based on Pareto. Metabolite identification of the oil palm leaves was determined by comparing the identified metabolite peaks with the Chenomx NMR Suite 7.7 library and standard NMR metabolite databases, i.e., the Human Metabolome Database (HMDB; http://www.hmdb.ca/).

2.6. Preparation of Modified Electrode. The modified electrode was prepared according to the method described previously [18-22]. Layer-by-layer (LBL) assembly was employed to modify the electrode The bare screen-printed carbon electrode (SPCE) was rinsed several times with deionized water and immersed into gold nanoparticle-carbon nanotube (AuNP-CNT) dispersion for $5 \mathrm{~min}$. Then, it was removed and immersed in deionized water for $2 \mathrm{~min}$. After that, it was removed. These steps were repeated twice to complete a cycle, thus coating a bilayer of the nanocomposite, AuNPCNT, and CTS-CNT on the electrode surface, namely, AuNP-aCNT/CTS-aCNT/SPE. This process was continued until four bilayers are successfully deposited on the substrate and labelled as BL4/SPCE. The developed electrodes were dried in an oven at $500^{\circ} \mathrm{C}$ for two hours and stored in desiccators until further analysis.

2.7. Characterization of Modified Electrode in Healthy and G. boninense-Infected Leaves. The characterization of the developed electrode was characterized in $100 \mathrm{mg} / \mathrm{L}$ healthy and $G$. boninense-infected oil palm leaves under the optimized conditions $(-0.52 \mathrm{~V}, 180 \mathrm{~s}$, and $0.06 \mathrm{~V} / \mathrm{s})$. The cyclic voltammetry (CV) and the linear sweep voltammetry (LSV) measurements were performed via a DropSens potentiostat $\mu$ Stat 8000 electrochemical workstation (Asturias, Spain), for reproducibility, sensitivity, and interference study of the developed electrode. The scanning potential was swept between $-0.6 \mathrm{~V}$ and $+0.6 \mathrm{~V}$.

\section{Results and Discussion}

3.1. ${ }^{1}$ H NMR Spectra and Metabolite Identification. Discrimination of the metabolite variation between healthy and $G$. boninense-infected oil palm leaves was employed using ${ }^{1} \mathrm{H}$ NMR metabolomics analysis. Figure 1 shows the ${ }^{1} \mathrm{H}-\mathrm{NMR}$ spectra of oil palm leaves extracts with identified metabolites. These metabolites including sugars, amino acids, and phenolics were identified based on the 2D J-resolved experiment (Figure 2) and comparison with the NMR spectra of the reference compounds measured under the same conditions as extracts. All of the spectra showed signals in the aliphatic $(\delta 0.5-3.0)$, carbohydrate $(\delta 3.0-5.5)$, and aromatic regions $(\delta 5.5-8.0)$.

The identified metabolites from oil palm leaves extracts and their characteristic signals are shown in Table 1. A total of 22 metabolites were identified, including primary and secondary metabolites. Isobutyric acid, 3-aminoisobutyric acid, $\beta$-cryptoxanthin, and alanine were present in the aliphatic region between $\delta 1.00$ and $\delta 1.92$ whereas $N$-acetylcysteine, homocysteine, and tyramine appeared between $\delta 2.04$ and $\delta$ 2.92 .

Alpha-glucose, arabinose, fructose, sucrose, and xylose were ascribed based on the signals displayed in the carbohydrate region of $\delta 3.0-\delta 5.5$. The presence of $\alpha$-glucose was confirmed by the peaks at $\delta 5.16(d, J=5.0 \mathrm{~Hz})$ whereas peaks of arabinose were detectable at $\delta 4.00(\mathrm{~m})$ and $\delta 3.90$ $(m)$. Fructose and xylose were detectable at $\delta 4.08(d, J=$ $5.0 \mathrm{~Hz})$ and $\delta 4.56(d, J=10.0 \mathrm{~Hz})$, respectively. Several peaks observed at $\delta 5.40(d, J=5.0 \mathrm{~Hz}), \delta 4.16(d, J=9.0$ $\mathrm{Hz})$, and $\delta 3.44(t, J=10.0 \mathrm{~Hz})$ suggested the presence of sucrose. Other metabolites detectable in the carbohydrate region were choline and indole-3-acetic acid which were detectable at $\delta 3.20(s)$ and $\delta 3.64(s)$, respectively.

Several phenolics and other metabolites were present in the aromatic region ( $\delta 5.5-8.0)$. Biotin, 2,3,4-trihydroxybenzoic acid, trans-aconitic acid, and kaempferol were determined between $\delta 6.40$ and $\delta$ 6.76. The characteristic peaks of gallic acid, caffeic acid, and $p$-hydroxybenzoic acid were detectable at $\delta 7.04, \delta 7.16$, and $\delta 8.01$, respectively.

3.2. Discrimination of Healthy and G. boninense-Infected Oil Palm Leaves at 14 Days Postinfection. Identification of metabolite variations of healthy and $G$. boninense-infected 


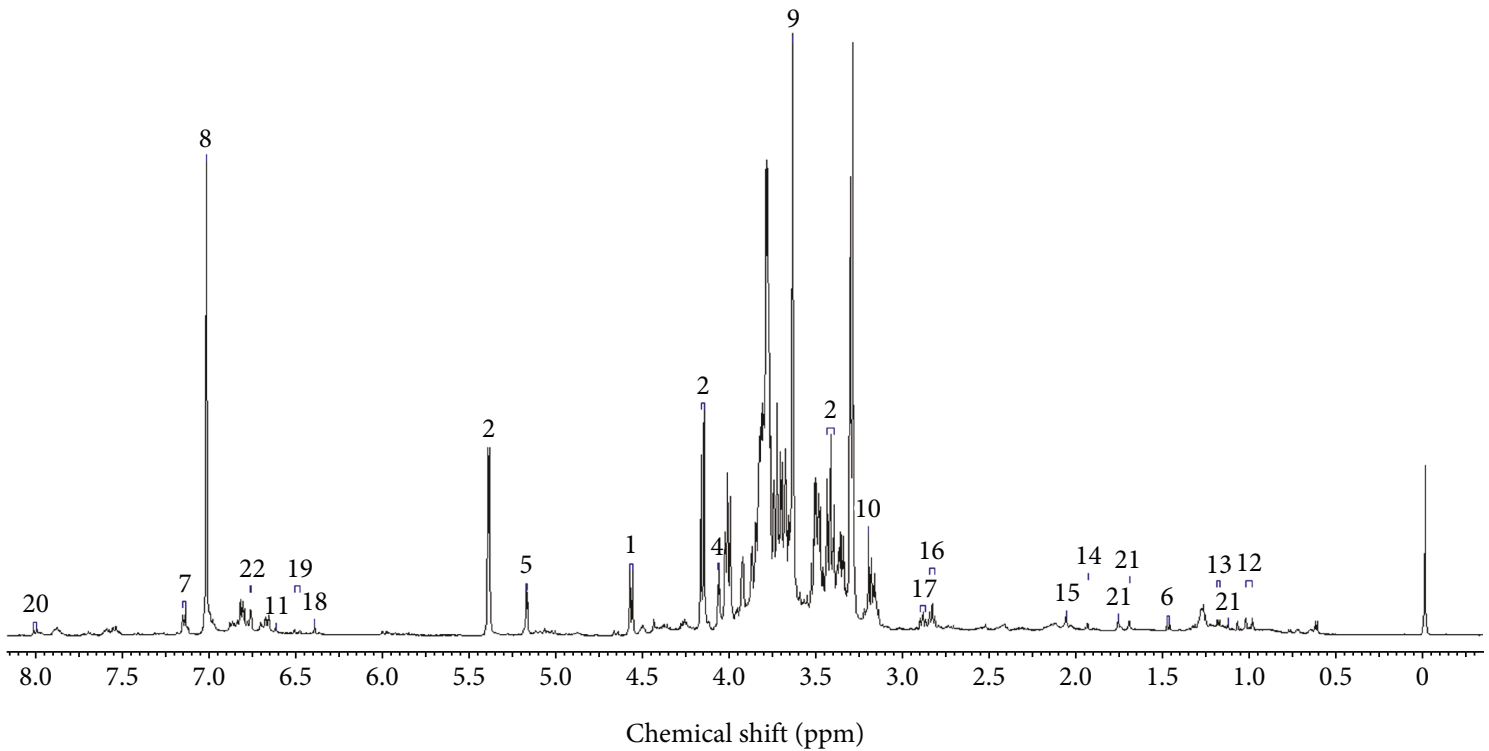

(a)

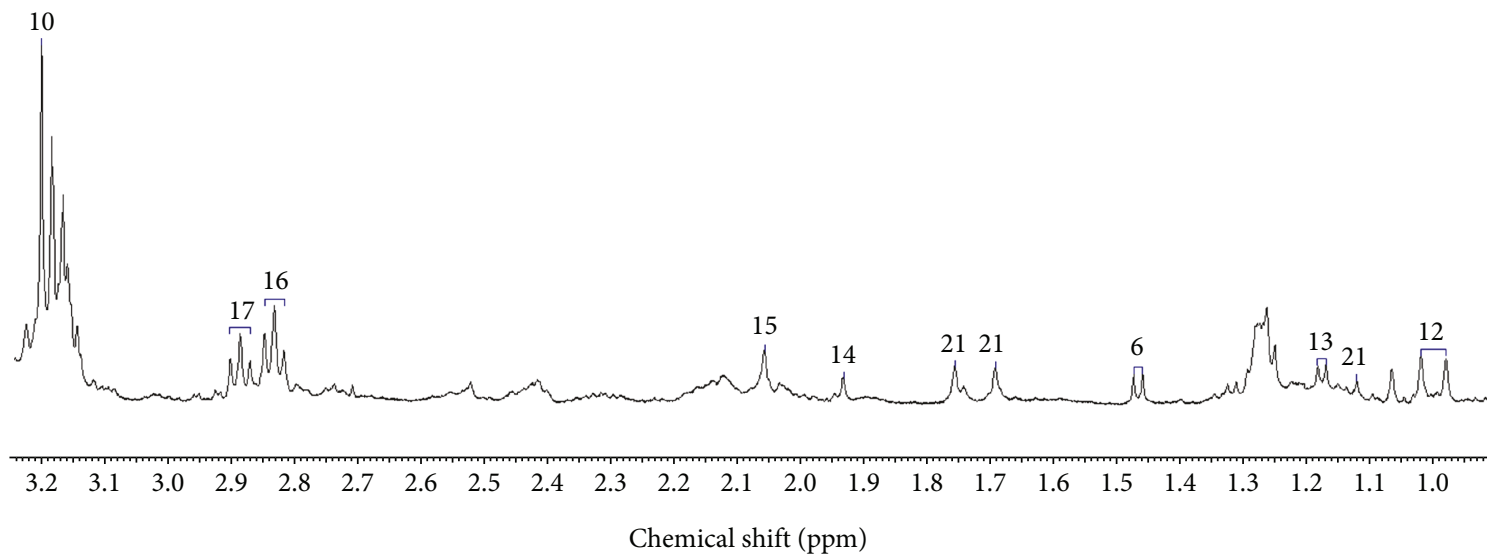

(b)

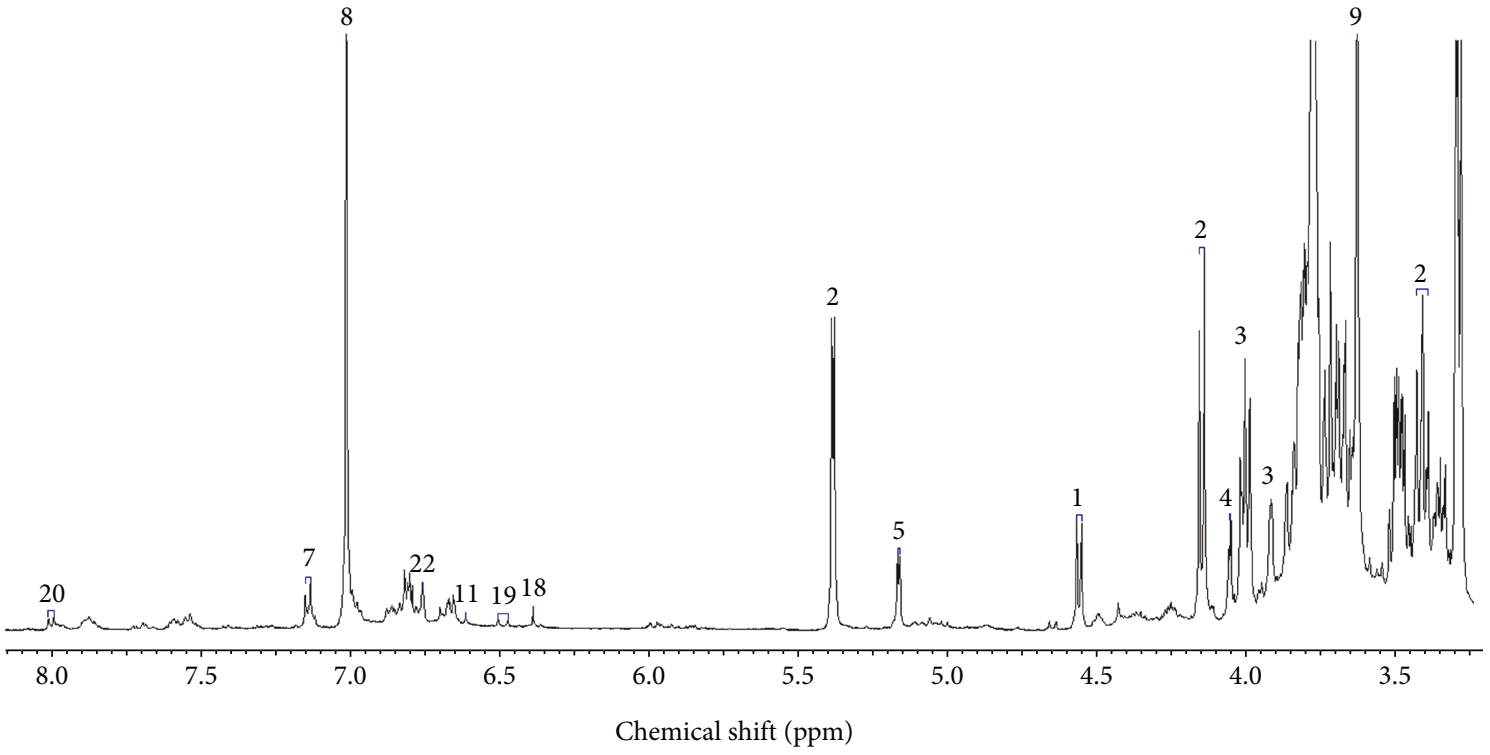

(c)

Figure 1: (a) ${ }^{1} \mathrm{H}$ NMR spectrum of oil palm leaves. (b) An expanded ${ }^{1} \mathrm{H}$ NMR spectrum between $\delta 0.50$ and $\delta 3.25$. (c) An expanded ${ }^{1} \mathrm{H}$ NMR spectrum between $\delta 3.45$ and $\delta 8.05$. 
Journal of Nanomaterials

5

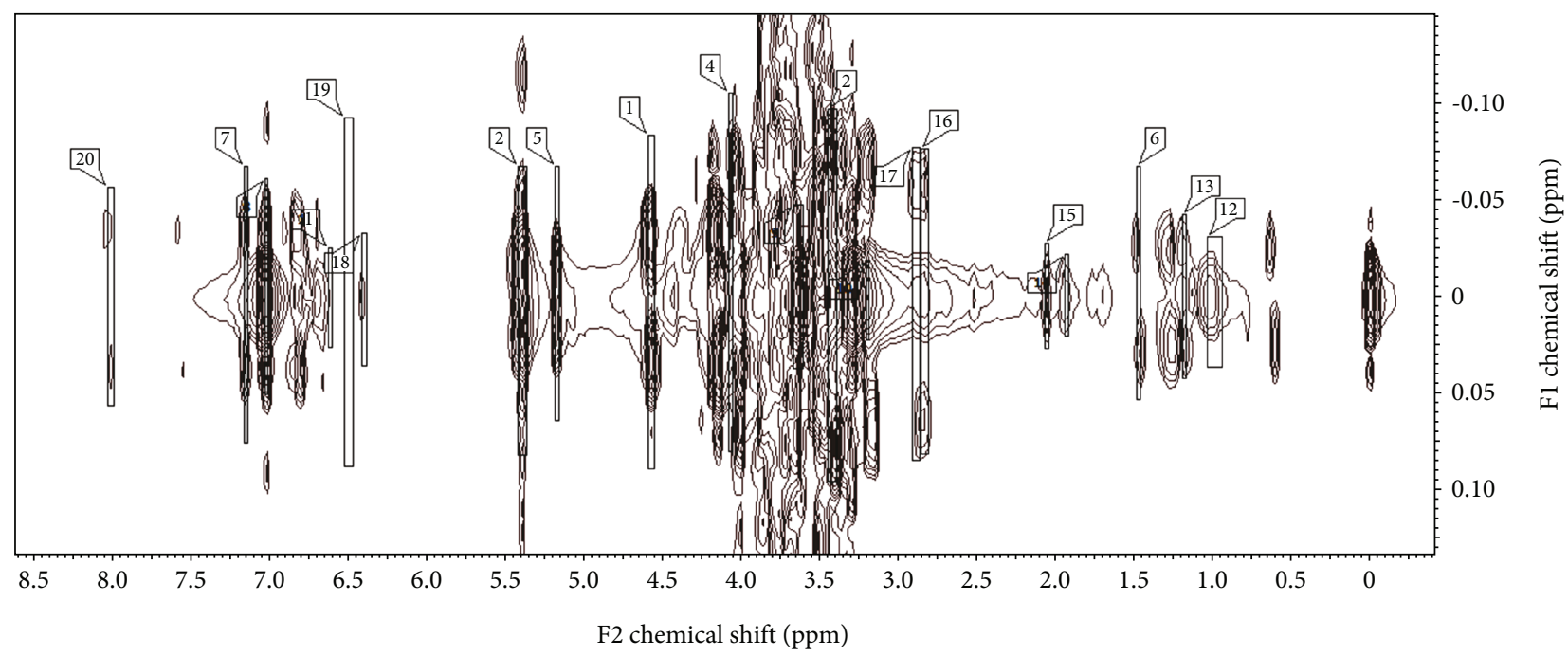

(a)

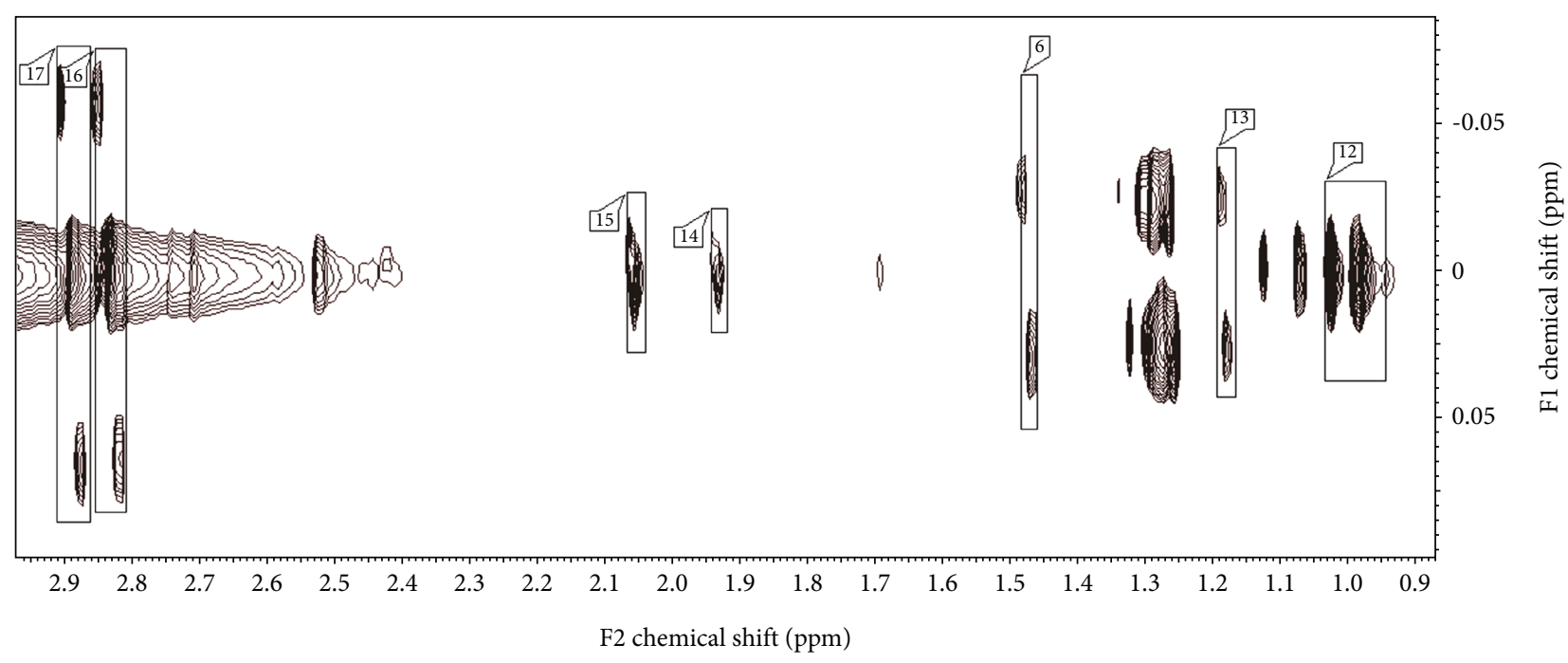

(b)

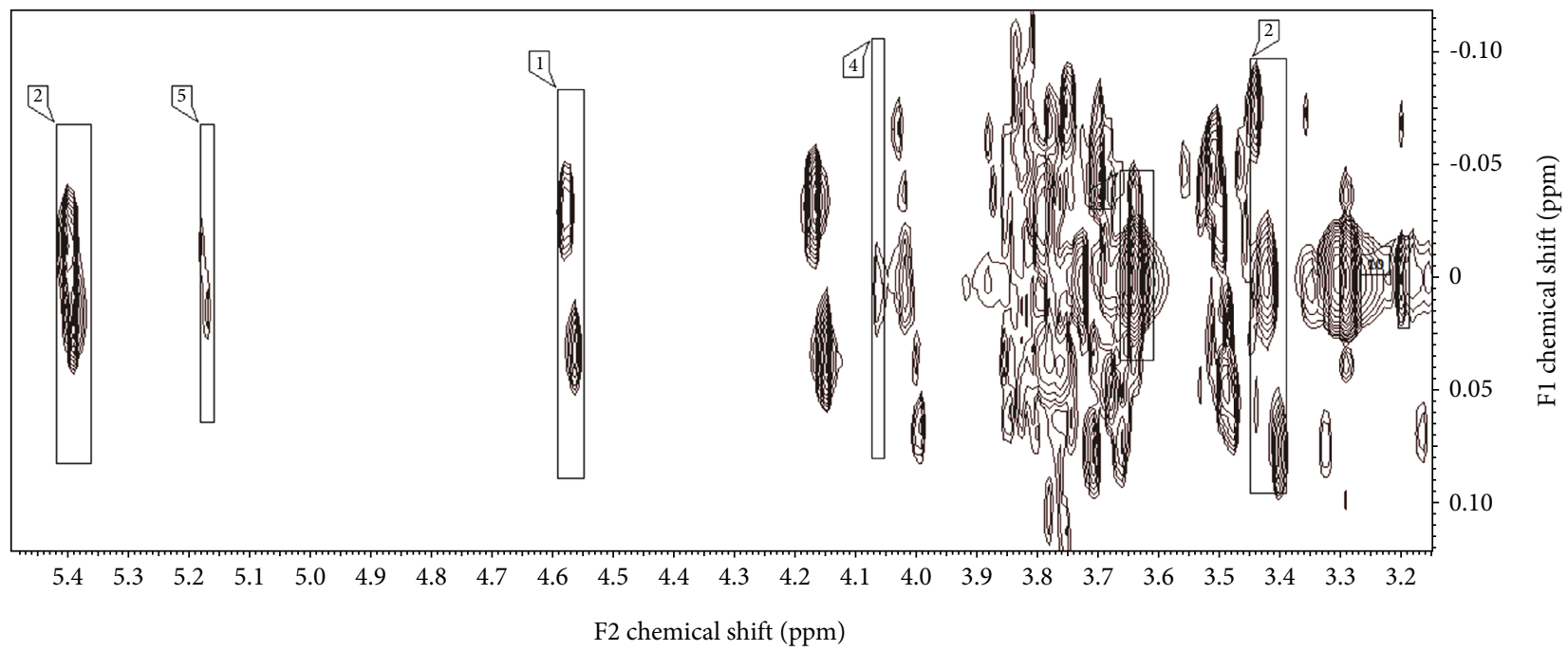

(c)

FIgUre 2: Continued. 


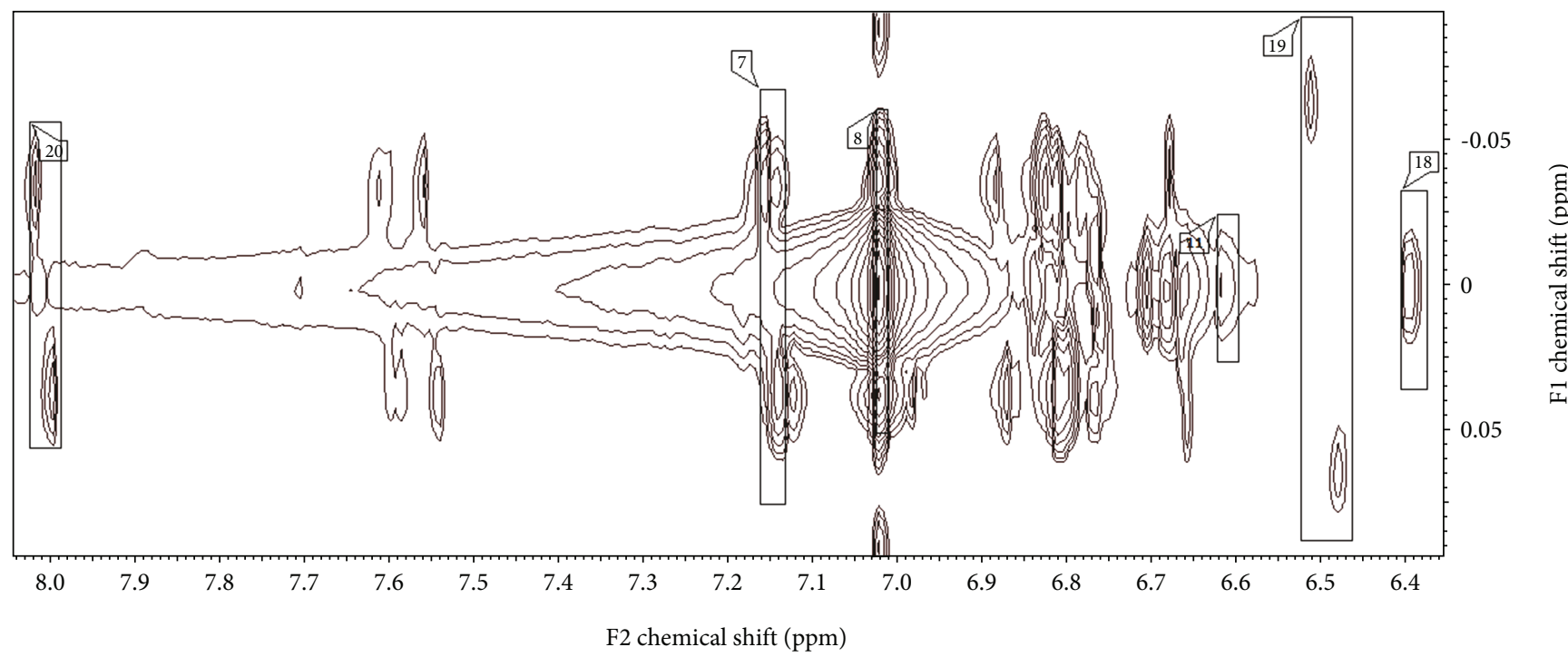

(d)

FIGURE 2: 2D J-resolved experiments of oil palm leaves: (a) in the region from $\delta$ - 0.50 to $\delta 8.50$; (b) in the region from $\delta 0.80$ to $\delta 2.93$; (c) in the region from $\delta 3.10$ to $\delta 5.50$; and (d) in the region from $\delta 6.30$ to $\delta 8.15$. For the interpretation of the numbers assigned to the metabolites in the $2 \mathrm{D} J$-resolved experiments, refer to Table 1.

TABLE 1: Assignments of NMR signals for metabolites identified in ${ }^{1} \mathrm{H}$ and 2D NMR spectra of oil palm leaves extracts with corresponding multiplicity ( $s$ : singlet; $d$ : doublet; $t$ : triplet; $m$ : multiplet) and scalar coupling constant $(J(\mathrm{~Hz}))$ values.

\begin{tabular}{|c|c|c|}
\hline Peak no. & Metabolites & Chemical shift (multiplicity, $J$ ) \\
\hline 1 & Xylose & $\delta 4.56(d, J=10.0 \mathrm{~Hz})$ \\
\hline 2 & Sucrose & $\delta 5.40(d, J=5.0 \mathrm{~Hz}), \delta 4.16(d, J=9.0 \mathrm{~Hz}), \delta 3.44(t, J=10.0 \mathrm{~Hz})$ \\
\hline 3 & Arabinose & $\delta 4.00(m), \delta 3.92(m)$ \\
\hline 4 & Fructose & $\delta 4.08(d, J=5.0 \mathrm{~Hz})$ \\
\hline 5 & $\alpha$-Glucose & $\delta 5.16(d, J=5.0 \mathrm{~Hz})$ \\
\hline 6 & Alanine & $\delta 1.48(d, J=10.0 \mathrm{~Hz})$ \\
\hline 7 & Caffeic acid & $\delta 7.16(d, J=10.0 \mathrm{~Hz})$ \\
\hline 8 & Gallic acid & $\delta 7.04(s)$ \\
\hline 9 & Indole-3-acetic acid & $\delta 3.64(s)$ \\
\hline 10 & Choline & $\delta 3.20(s)$ \\
\hline 11 & trans-Aconitic acid & $\delta 6.60(s)$ \\
\hline 12 & Isobutyric acid & $\delta 1.00(d, J=20.0 \mathrm{~Hz})$ \\
\hline 13 & 3-Aminoisobutyric acid & $\delta 1.19(d, J=10.0 \mathrm{~Hz})$ \\
\hline 14 & $N$-Acetyltyrosine & $\delta 1.92(s)$ \\
\hline 15 & $N$-Acetylcysteine & $\delta 2.04(s)$ \\
\hline 16 & Homocysteine & $\delta 2.84(t, J=10.0 \mathrm{~Hz})$ \\
\hline 17 & Tyramine & $\delta 2.92(t, J=5.0 \mathrm{~Hz})$ \\
\hline 18 & Biotin & $\delta 6.40(s)$ \\
\hline 19 & 2,3,4-Trihydroxybenzoic acid & $\delta 6.52(d, J=15.0 \mathrm{~Hz})$ \\
\hline 20 & p-Hydroxybenzoic acid & $\delta 8.01(d, J=5.0 \mathrm{~Hz})$ \\
\hline 21 & $\beta$-Cryptoxanthin & $\delta 1.76(s), \delta 1.68(s), \delta 1.12(s)$ \\
\hline 22 & Kaempferol & $\delta 6.76(d, J=2.5 \mathrm{~Hz})$ \\
\hline
\end{tabular}

oil palm leaves was done by principal component analysis (PCA). PCA was used to cluster the features of the samples and analyze the metabolites that contributed to the variation.

Healthy and G. boninense-infected oil palm leaves at 14 days postinfection could be discriminated clearly as shown in Figure 3(a). The first two principal components (PC1 and PC2) cumulatively accounted for $87.5 \%$ of the total variation. Separation of the healthy and G. boninense infected oil palm leaves in score plots was achieved by combining PC1 and PC2. 


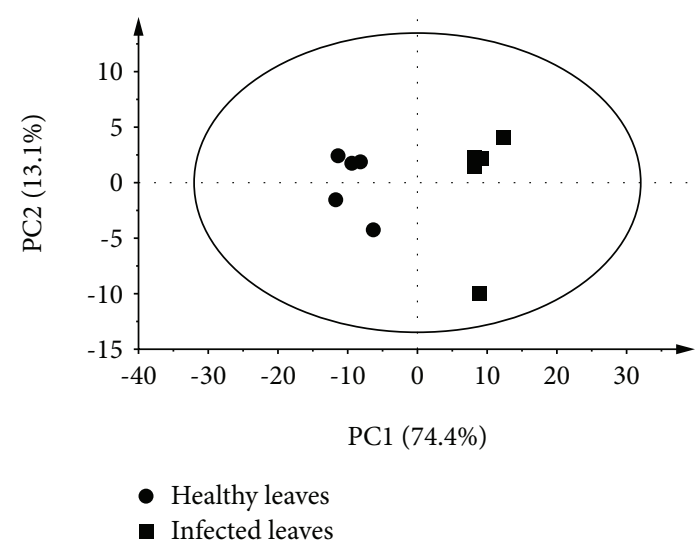

(a)

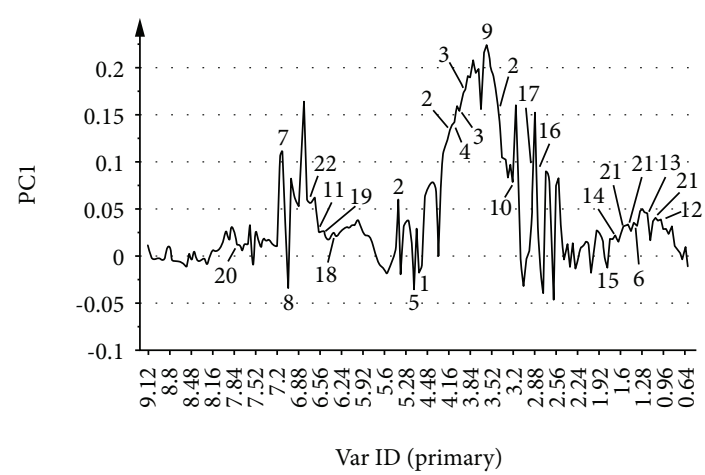

(b)

FIGURE 3: (a) PCA score plot (component 1 vs. component 2) and (b) loading line plot of component 1 of ${ }^{1} \mathrm{H}$ NMR data for comparing healthy and G. boninense-infected oil palm leaves at 14 days of infection. For the interpretation of the numbers assigned to the metabolites in the loading column plot, refer to Table 1.

The metabolites in the healthy and G. boninense-infected oil palm leaves which could be illustrious using PCA is shown in the loading line plot for PC1 (Figure 3(b)). The PCA and loading line plots correlate with each other. The position of an object in a given direction within the score plot is influenced by a variable which lies in the same direction in the loading plot [23].

From the PCA analysis, the levels of xylose, $\alpha$-glucose, gallic acid, and $\mathrm{N}$-acetylcysteine were more abundant in healthy leaves whereas sucrose, arabinose, fructose, alanine, caffeic acid, indole-3-acetic acid, choline, trans-aconitic acid, isobutyric acid, 3-aminoisobutyric acid, $\mathrm{N}$-acetyltyrosine, homocysteine, tyramine, biotin, 2,3,4-trihydroxybenzoic acid, $p$-hydroxybenzoic acid, $\beta$-cryptoxanthin, and kaempferol levels were higher in $G$. boninense-infected leaves.

Primary metabolites which are produced by plant cells are directly involved in growth, development, and reproduction, whereas the secondary metabolites such as alkaloids, terpenoids, compounds containing sulphur, and phenolics are involved in host defense response [24].

Sugars play important roles as carbon and energy sources [25]. Also, they have been recognized as signaling molecules of plant defense under biotic and abiotic stresses [26-30]. Accumulation of sucrose and fructose in $G$. boninenseinfected leaves should be related to their role as energy sources for pathogen replication [31].

In contrast, $\alpha$-glucose was decreased in infected leaves which indicated a part of the available carbon gathered in carbohydrates is conceivably diverted towards secondary metabolism. The carbohydrates also provide the necessary energy to support increased secondary metabolite biosynthesis [32].

The high level of alanine in G. boninense-infected leaves was observed in the present study. Similarly, Vitis vinifera showed increased levels of alanine when infected with Botrytis cinerea, demonstrating its defensive role against biotic stresses [33]. It has been suggested that alanine synthesis is increased to regulate cellular osmosis which is decreased by high cellular carbohydrate levels under stress conditions in infected plants wherein $\gamma$-aminobutyric acid (GABA) catabolism by GABA transaminase leads to alanine accumulation [33-36].

Meanwhile, accumulation of choline amount in infected leaves is associated to an increase in the synthesis of membrane components after pathogen infection. It has been reported that infected leaves induce choline synthesis through the jasmonic acid signal transduction pathway [37].

Phenolics such as kaempferol, 2,3,4-trihydroxybenzoic acid, p-hydroxybenzoic acids, and caffeic acid level were more prominent in G. boninense-infected leaves. These metabolites were produced by plants to help in cell wall lignifications [38], antimicrobial activity [39, 40], modulation of plant hormones involved in defense signaling pathways, and scavenging of reactive oxygen species [41].

Indole-3-acetic acid (IAA) level was found higher in infected leaves which coincided with previous studies on metabolic changes in Agrobacterium tumefaciens-infected Brassica rapa. IAA acts as an inhibitor of virulence gene expression in plants. It also functions as a chemical agent metabolite in plant defense against pathogen [42].

\subsection{Electrochemical Characterization of Modified Electrode} for Healthy and G. boninense-Infected Oil Palm Leaves at 14 Days Postinfection. Our coauthor has characterized previously the morphological structures of MWCNT and AuNPaMWCNT composites using an ultrahigh resolution field emission scanning electron microscope (FESEM) [22]. The pristine-MWCNT shows a uniform and equivalent tubular arrangement with some voids. The tubes were not shortened on activation even the spaces are closed up to an extent $[22,43]$. Unevenness of the surface was observed in their finding after activation due to the attachment of carboxylic functional groups to the surface. The surface of aMWCNT was craggier with the incorporation of AuNPs which confirm successful loading of AuNPs on the aMWCNT [22].

The modification of the surface of the bare SPCE via LBL self-assembly approach was characterized using FESEM by Akanbi et al. [22]. They reported that the gradual coverage 


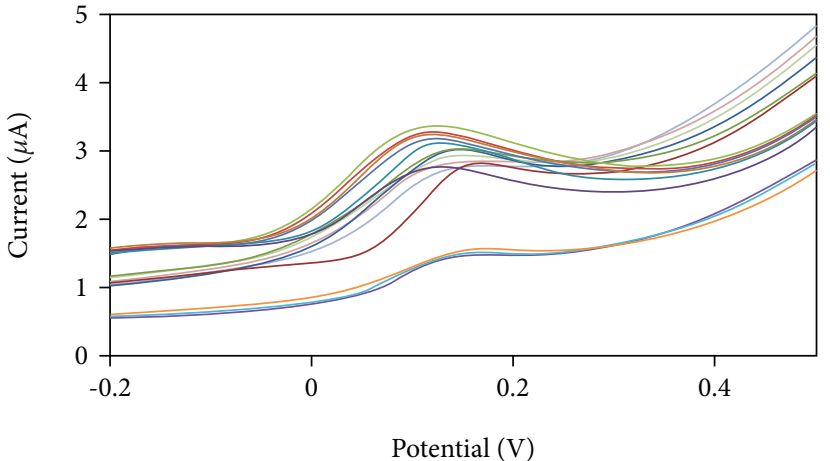

(i)

(a)

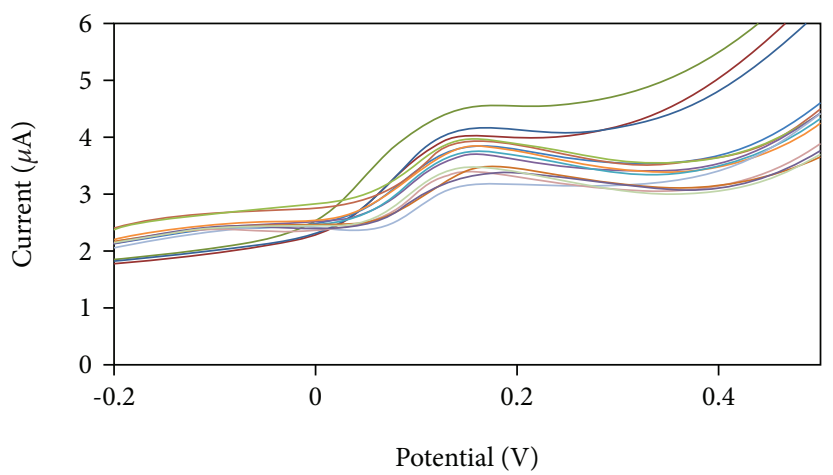

(i)

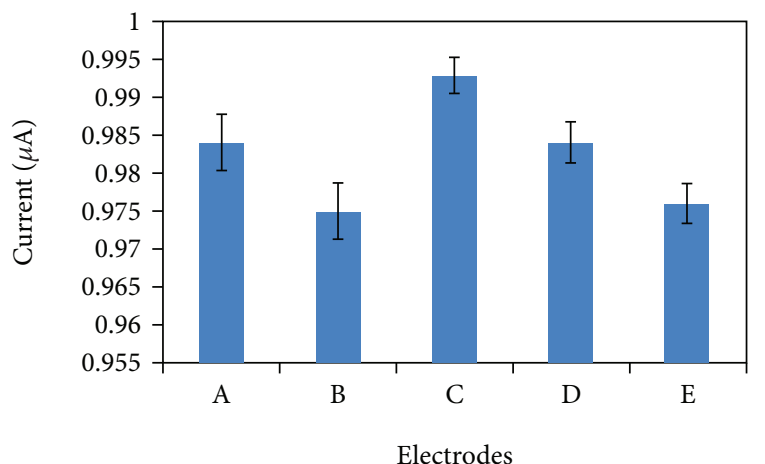

(ii)

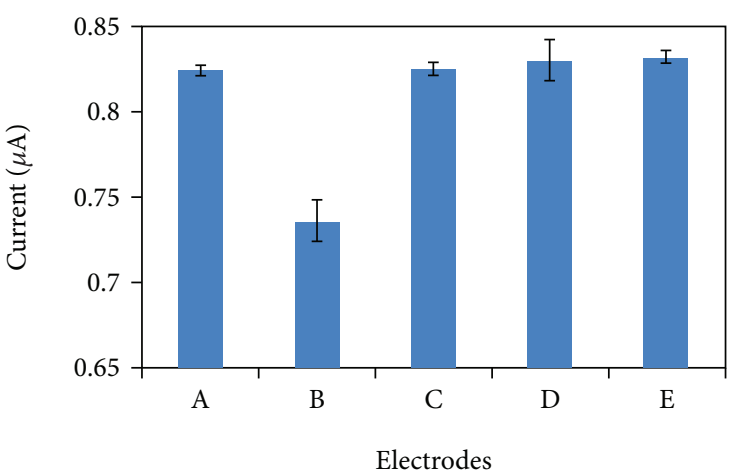

(ii)

(b)

Figure 4: LSVs of five replicates independently produced BL4/SPCEs in $100 \mathrm{mg} / \mathrm{L}$ (a) (i) healthy leaves and (b) (i) G. boninense-infected leaves. A plot of anodic peak current versus regenerated BL4/SPCEs in (a) (ii) healthy leaves and (b) (ii) G. boninense-infected leaves.

of the surface of the SPCE as the numbers of bilayers of nanohybrid materials increases. The presence of AuNPs assisted the catalytic properties of the MWCNT, while chitosan nanoparticles affect proper binding tendency towards the analyte via its functional groups. These beneficial effects largely improve the overall performance of the developed electrode, which is apparent in the electronic transition enhancement. When the surface of the SPCE is almost covered, the further deposition of nanohybrid materials may lead to excessive deposition, which may retard electron movement to the site of chemical reaction on the electrode platform.

Akanbi et al. also studied the functional group presence in the MWCNTs, a-MWCNTs, and CTSNP-aMWCNT using Fourier-transform infrared spectroscopy [22]. Functional groups of $(-\mathrm{N}-\mathrm{H},-\mathrm{O}-\mathrm{H}),(\mathrm{C}=\mathrm{O})$, and $(\mathrm{C}-\mathrm{N})$ were observed in CTSNP-aMWCNT composites whereas $\mathrm{C}-\mathrm{H}$ bond which is a dominating bond was present in pristineMWCNTs. Other functional groups determined were $(\mathrm{C}=\mathrm{O}),(-\mathrm{O}-\mathrm{H})$, and $(-\mathrm{C}-\mathrm{O})$, indicating the carboxylation of the pristine-MWCNTs [22].

The characterization of the modified electrode was conducted utilizing the linear sweep voltammetric method under optimized conditions of $-0.52 \mathrm{~V}$ accumulation potential, $180 \mathrm{~s}$ accumulation time, and a scan rate of $0.06 \mathrm{~V} / \mathrm{s}$. The potential was scanned from $-0.6 \mathrm{~V}$ to $+0.6 \mathrm{~V}$ with a potential step of $0.002 \mathrm{~V}$ and an equilibrium time of $10 \mathrm{~s}$.
3.3.1. Reproducibility Study. Figure 4 shows LS voltammograms of $100 \mathrm{mg} / \mathrm{L}$ healthy and $G$. boninense-infected leaves at the platform of five independently prepared BL4/SPCEs (Figures 4(a) (i) and 4(b) (i)). Five replicates of BL4/SPCEs were prepared independently to determine the oxidation anodic peak current and Ipa response of $100 \mathrm{mg} / \mathrm{L}$ healthy and $G$. boninense-infected leaves in the absence of supporting electrolyte (Figures 4(a) (ii) and 4(b) (ii)). The peak potential at the five BL4/SPCEs for each of healthy and G. boninenseinfected leaves approximates in the range of $0.10-0.20 \mathrm{~V}$. The calculated relative standard deviation (RSD) from the plot of healthy and G. boninense-infected leaves was $0.73 \%$ and $5.08 \%$, respectively. The RSD value for healthy leaves may suggest that all the five differently modified electrodes gave approximately the same oxidation anodic current response towards the oxidation of healthy leaves. Consequently, there is divergent response at the surface of the other five modified electrodes towards the oxidation of $G$. boninense-infected leaves at 14 days postinfection. This value implies that the electrode is reproducible.

3.3.2. Sensitivity Study. The linear-sweep voltammograms shown in Figures 5(a) (i and ii) and 5(b) (i and ii) demonstrate the excellent response of the BL4/SPCE sensor provided as a function of the healthy and $G$. boninense-infected leaves concentration in the absence of a supporting 


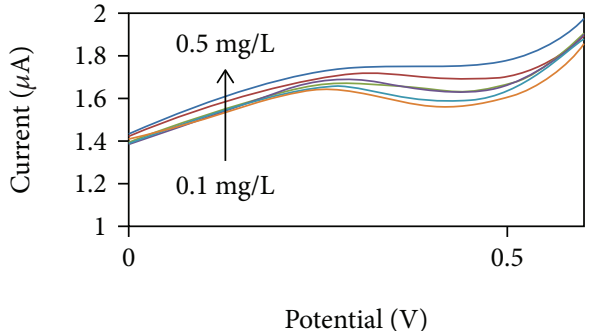

(i)

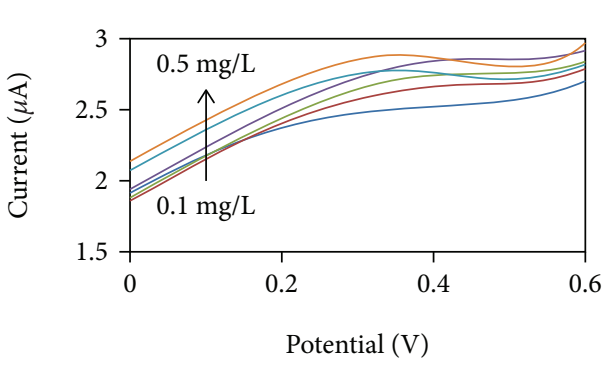

(i)

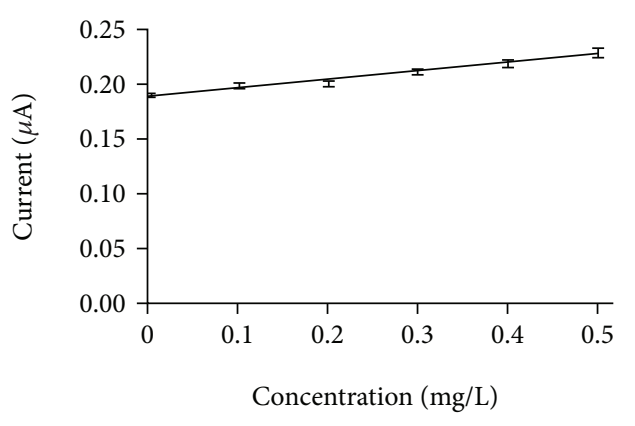

(ii)

(a)

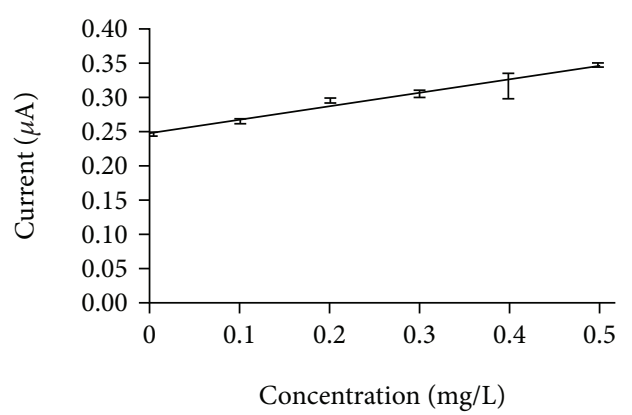

(ii)

(b)

Figure 5: Linear sweep voltammograms of BL4/SPCE in different concentrations of (a) (i) healthy leaves and (b) (i) G. boninense-infected leaves, and linear relationship of anodic peak current, Ipa, and concentrations of (a) (ii) healthy leaves and (b) (ii) G. boninense-infected leaves.

TABLE 2: Comparison of electroanalytical data of various modified electrodes.

\begin{tabular}{lccc}
\hline Modifier & Detection & Limit of detection $(\mathrm{mg} / \mathrm{L})$ & References \\
\hline ZnO-rGO-GCE & Hydrogen peroxide & 0.068 & {$[43]$} \\
Poly(vinylpyrrolidone)-modified carbon-paste electrode & Quercetin & 0.051 & {$[44]$} \\
ZnO-rGO-GCE & Ascorbic acid & 0.055 & {$[45]$} \\
\hline
\end{tabular}

electrolyte. It is evident that as the anodic peak current increases, there was a slight shift in the peak potential as the concentration of the samples is elevated. This may be attributed to the catalytic effect of the nanocomposite hybrid surface modifiers on the chemical composition of the samples.

The corresponding calibration curves obtained from Figures 5(a) (i) and 5(b) (i) are adjacently shown in Figures 5(a) (ii) and 5(b) (ii). The calibration curves obtained for the oxidation of healthy and $G$. boninense-infected leaves are linear in the concentration range of 0.1 to $0.5 \mathrm{mg} / \mathrm{L}$. The linear regression equation for healthy leaves can be expressed according to the function Ipa $(\mu \mathrm{A})=0.1901+0.0754$ (correlation coefficient $\left.\left(R^{2}\right)=0.9732\right)$ whereas the linear regression equation for $G$. boninense-infected leaves was Ipa $(\mu \mathrm{A})=$ $0.2502+0.1913$ (correlation coefficient $\left(R^{2}\right)=0.9716$ )

The difference observed between the anodic peak current values of healthy and G. boninense-infected leaves crude extract solution is resulted by the abundance of the higher level of secondary metabolites such as phenolic compounds (kaempferol, 2,3,4-trihydroxybenzoic acid, p-hydroxyben- zoic acids, and caffeic acid) and auxin (indole-3-acetic acid) in the G. boninense-infected leaves crude extract. In addition, the primary metabolites such as sugars and amino acids were also contributed to the difference.

The limit of detection (LOD) was calculated according to the following equation: $\mathrm{LOD}=3.3 \mathrm{Sb} / \mathrm{B}$, where $\mathrm{Sb}$ is the standard deviation of the linear coefficient and $B$ is the slope of the calibration curve. The LOD value obtained for healthy leaves crude extracts was calculated to $0.0765 \mathrm{mg} / \mathrm{L}$ whereas the LOD value for $G$. boninense-infected leaves crude extracts was $0.0414 \mathrm{mg} / \mathrm{L}$. As shown in Table 2, the LOD of the G. boninense-infected leaves crude extract electrode has been compared with other reported previously [44-46]. It can be suggested that the low LODs of the pair AuNP-aMWCNT and ChTSNP-aMWCNT nanohybrid materials could be suitable for the modification of screen-printed carbon electrodes for the detection of healthy and G. boninense-infected leaves.

3.3.3. Interference Study. The changes in the response of the anodic peak current (Ipa) of the healthy and G. boninense- 


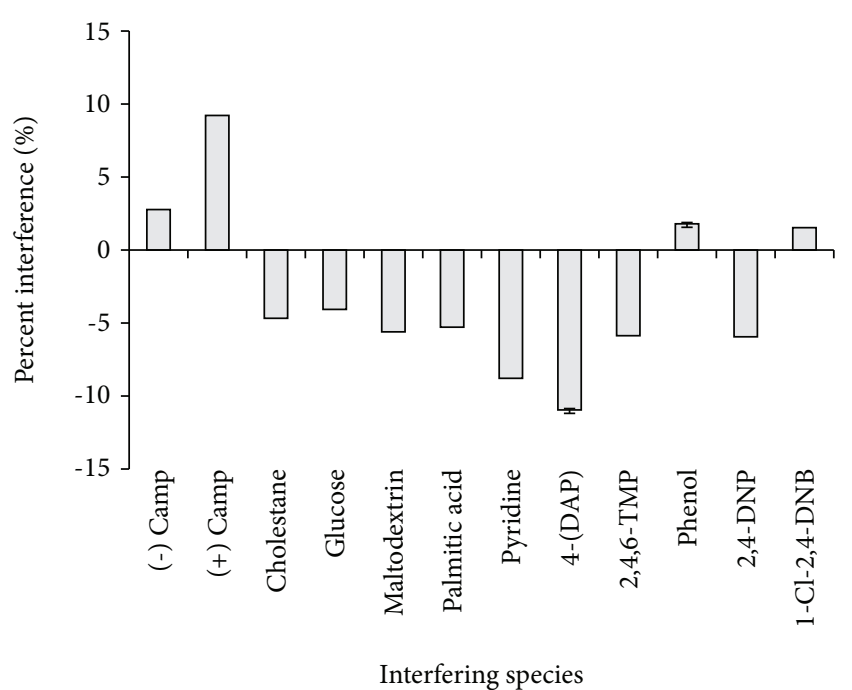

(a)

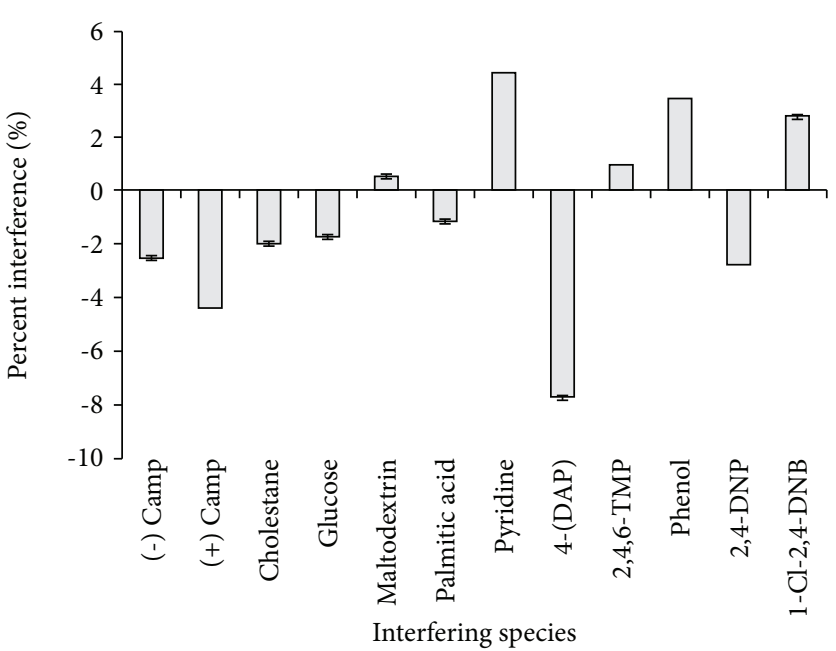

(b)

FIgURe 6: A plot of percent interference in the anodic peak current (Ipa) response of (a) healthy leaves and (b) G. boninense-infected leaves against interfering species at modified electrode under optimized conditions (-0.53 V, $180 \mathrm{~s}, 0.06 \mathrm{~V} / \mathrm{s})$. (-) campherochinon: (-) Camp; (+) campherochinon: (+) Camp; 4-(dimethyl amino)pyridine: 4-(DAP); 2,4,6-trimethylpyridine: 2,4,6-TMP; 2,4-dinitrophenol: 2,4-DNP; 1chloro-2,4-dinitrobenzene: 1-Cl-2,4-DNB.

infected leaves at the developed electrode platform were measured in the presence of different potential interferences (Figure 6). These interferences were predominantly organic due to the nature of the sample being considered. They include (-) campherochinon, (+) campherochinon, glucose, palmitic acid, pyridine, maltodextrin, cholestane, phenol, 4(dimethyl amino)pyridine, 2,4,6-trimethylpyridine, 1chloro-2,4-dinitrobenzene, and 2,4-dinitrophenol. 500-fold excess concentration of each interference was prepared for this determination. The obtained signal for a fixed concentration of each leaves was compared with the signal values obtained in the presence of known concentrations of the employed interfering species. The tolerance limit was considered the maximum concentration of interfering species that cause an error less than or greater than $10 \%$ for the detection of healthy and G. boninense-infected leaves. As displayed in Figures 6(a) and 6(b), a closer look at Figure 6(a) revealed that $(+)$ campherochinon, pyridine, and 4-(dimethyl amino)pyridine interfered with the detection of healthy leaves. However, it is 4-(dimethyl amino)pyridine that is said to be the strongest in interference with a percent interference greater than $-10 \%$. In the case of $G$. boninense-infected leaves (Figure 6(b)), the effects of the interference is negligible, though 4-(dimethyl amino)pyridine still possesses the highest percent interference of almost $-8 \%$.

\section{Conclusion}

It can be concluded that NMR spectra of healthy and $G$. boninense-infected leaves at 14 days postinfection exhibited differences which were discriminated and clustered into groups through multivariate data analysis of PCA. AuNP-aCNT and CTS-aCNT nanocomposite were successfully prepared via a simple method and used to fabricate a novel electrode for the electrochemical detection of healthy and G. boninense-infected leaves. The AuNPaMWCNT/ChTSNP-aMWCNT film was found to enhance the electrooxidation activity of healthy and G. boninenseinfected leaves, due to the catalysis of AuNPs, binding potential of CTSNPs, and wide surface area provided by aMWCNTs. The results show good signal enhancement of healthy and G. boninense-infected leaves on AuNPaMWCNT/ChTSNP-aMWCNT ultrathin films which offer a new sensitive, selective, cost-effective, and environmentally friendly electrode.

\section{Data Availability}

The data used to support the findings of this study are available from the corresponding authors upon request.

\section{Conflicts of Interest}

The authors declare that there is no conflict of interest regarding the publication of this paper.

\section{Acknowledgments}

This work was supported by the Ministry of Higher Education Malaysia, Long Term Research Grant Scheme(LRGS-) Nanomite, and Universiti Putra Malaysia under Grant nos. 5526301, 5526304, 9443101 and 9443104.

\section{References}

[1] J. Flood, Y. Hasan, P. D. Turner, and E. B. O'Grady, "The spread of Ganoderma from infective sources in the field and its implications for management of the disease in oil palm," in Ganoderma Diseases of Perennial Crops, J. Flood, P. D. Bridge, and M. Holderness, Eds., pp. 101-112, CABI Publishing, Wallingford, UK, 2000. 
[2] R. H. V. Corley and P. B. Tinker, The Oil Palm, Blackwell Science, Oxford, UK, 4th edition, 2003.

[3] A. Roslan and A. S. Idris, "Economic impact of Ganoderma incidence on Malaysian oil palm plantation - a case study in Johor," Oil Palm Industry Economic Journal, vol. 12, pp. 2430, 2012.

[4] S. M. Kok, Y. K. Goh, H. J. Tung, K. J. Goh, W. C. Wong, and Y. K. Goh, "In vitro growth of Ganoderma boninense isolates on novel palm extract medium and virulence on oil palm (Elaeis guineensis) seedlings," Malaysian Journal of Microbiology, vol. 9, no. 1, pp. 33-42, 2013.

[5] J. Al-Obaidi, Y. Mohd-Yusuf, N. Razali et al., "Identification of proteins of altered abundance in oil palm infected with Ganoderma boninense," International Journal of Molecular Sciences, vol. 15, no. 3, pp. 5175-5192, 2014.

[6] G. A. Nagana Gowda and D. Raftery, "Can NMR solve some significant challenges in metabolomics?," Journal of Magnetic Resonance, vol. 260, pp. 144-160, 2015.

[7] Y. Fang and R. Ramasamy, "Current and prospective methods for plant disease detection," Biosensors, vol. 5, no. 3, pp. 537$561,2015$.

[8] J. M. Henson and R. French, "The Polymerase Chain Reaction and Plant Disease Diagnosis," Annual Review of Phytopathology, vol. 31, no. 1, pp. 81-109, 1993.

[9] N. A. Yusof, S. F. Abd Rahman, and A. Muhammad, "Carbon nanotubes and graphene for sensor technology," in Synthesis, Technology and Applications of Carbon Nanomaterials, S. Abdul Rashid, R. N. I. Raja Othman, and M. Z. Hussein, Eds., pp. 205-222, Elsevier, 2019.

[10] B. Pan and B. Xing, "Adsorption mechanisms of organic chemicals on carbon nanotubes," Environmental Science and Technology, vol. 42, no. 24, pp. 9005-9013, 2008.

[11] S. Zhang, T. Shao, H. S. Kose, and T. Karanfil, "Adsorption of aromatic compounds by carbonaceous adsorbents: a comparative study on granular activated carbon, activated carbon fiber, and carbon nanotubes," Environmental Science and Technology, vol. 44, no. 16, pp. 6377-6383, 2010.

[12] H. Hyung and J. H. Kim, "Natural organic matter (NOM) adsorption to multi-walled carbon nanotubes: effect of NOM characteristics and water quality parameters," Environmental Science and Technology, vol. 42, no. 12, pp. 4416-4421, 2008.

[13] X. Zhou, S. Liu, A. Xu et al., "A multi-walled carbon nanotube electrode based on porous Graphite- $\mathrm{RuO}_{2}$ in electrochemical filter for pyrrole degradation," Chemical Engineering Journal, vol. 330, pp. 956-964, 2017.

[14] Y. Liang, J. Li, and Y. Zhao, "Poly(sulfosalicylic acid)/multiwalled carbon nanotube modified electrode for the electrochemical detection of catechol," International Journal of Electrochemical Science, vol. 12, pp. 9512-9522, 2017.

[15] S. Sadeghi and A. Garmroodi, "A highly sensitive and selective electrochemical sensor for determination of $\mathrm{Cr}(\mathrm{VI})$ in the presence of $\mathrm{Cr}$ (III) using modified multi-walled carbon nanotubes/quercetin screen-printed electrode," Materials Science and Engineering: C, vol. 33, no. 8, pp. 4972-4977, 2013.

[16] A. S. Idris, A. Kushairi, D. Ariffin, and M. W. Basri, Technique for inoculation of oil palm geminated seeds with Ganoderma, MPOB Information Series, No. 314, Selangor, Malaysia, 2006.

[17] H. K. Kim, Y. H. Choi, and R. Verpoorte, "NMR-based plant metabolomics: where do we stand, where do we go?," Trends in Biotechnology, vol. 29, no. 6, pp. 267-275, 2011.
[18] J. Manso, L. Agüí, P. Yáñez-Sedeño, and J. M. Pingarrón, "Development and characterization of colloidal goldcysteamine-carbon paste electrodes," Analytical Letters, vol. 37, no. 5, pp. 887-902, 2004.

[19] Z. Huang, L. Xi, Q. Subhani, W. Yan, W. Guo, and Y. Zhu, "Covalent functionalization of multi-walled carbon nanotubes with quaternary ammonium groups and its application in ion chromatography," Carbon, vol. 62, pp. 127-134, 2013.

[20] Z.-Y. Zhang and X.-C. Xu, "Nondestructive covalent functionalization of carbon nanotubes by selective oxidation of the original defects with $\mathrm{K}_{2} \mathrm{FeO}_{4}$," Applied Surface Science, vol. 346, pp. 520-527, 2015.

[21] Y. Zheng, L. Fu, A. Wang, and W. Cai, "Electrochemical detection of quinoline yellow in soft drinks based on layer-by-layer fabricated multi-walled carbon nanotube," International Journal of Electrochemical Science, vol. 10, pp. 3530-3538, 2015.

[22] F. Akanbi, N. Yusof, J. Abdullah, Y. Sulaiman, and R. Hushiarian, "Detection of quinoline in G. boninenseinfected plants using functionalized multi-walled carbon nanotubes: a field study," Sensors, vol. 17, no. 7, p. 1538, 2017.

[23] H. K. Choi, J. H. Yoon, Y. S. Kim, and D. Y. Kwon, "Metabolomic profiling of Cheonggukjang during fermentation by ${ }^{1} \mathrm{H}$ NMR spectrometry and principal components analysis," Process Biochemistry, vol. 42, no. 2, pp. 263-266, 2007.

[24] M. Mazid, T. A. Khan, and F. Mohammad, "Role of secondary metabolites in defense mechanisms of plants," Biology and Medicine, vol. 3, pp. 232-249, 2011.

[25] K. Koch, "Sucrose metabolism: regulatory mechanisms and pivotal roles in sugar sensing and plant development," Current Opinion in Plant Biology, vol. 7, no. 3, pp. 235-246, 2004.

[26] K. Herbers, P. Meuwly, J. P. Métraux, and U. Sonnewald, "Salicylic acid-independent induction of pathogenesis related protein transcripts by sugars is dependent on leaf developmental stage," FEBS Letters, vol. 397, no. 2-3, pp. 239-244, 1996.

[27] I. Morkunas, Ł. Marczak, J. Stachowiak, and M. Stobiecki, "Sucrose-induced lupine defense against Fusarium oxysporum: sucrose-stimulated accumulation of isoflavonoids as a defense response of lupine to Fusarium oxysporum," Plant Physiology and Biochemistry, vol. 43, no. 4, pp. 363-373, 2005.

[28] F. Rolland, E. Baena-Gonzalez, and J. Sheen, "Sugar sensing and signaling in plants: conserved and novel mechanisms," Annual Review of Plant Biology, vol. 57, no. 1, pp. 675-709, 2006.

[29] M. R. Bolouri-Moghaddam, K. Le Roy, L. Xiang, F. Rolland, and W. Van den Ende, "Sugar signalling and antioxidant network connections in plant cells: sugar signalling and antioxidant networks in plants," FEBS Journal, vol. 277, no. 9, pp. 2022-2037, 2010.

[30] D. N. Wijaya, F. A. Susanto, Y. A. Purwestri, D. Ismoyowati, and T. R. Nuringtyas, "NMR metabolite comparison of local pigmented rice in Yogyakarta," Indonesian Journal of Biotechnology, vol. 22, no. 2, pp. 68-75, 2018.

[31] D. Shalitin and S. Wolf, "Cucumber mosaic virus infection affects sugar transport in melon plants," Plant Physiology, vol. 123, no. 2, pp. 597-604, 2000.

[32] O. Hendrawati, Q. Yao, H. K. Kim et al., "Metabolic differentiation of Arabidopsis treated with methyl jasmonate using nuclear magnetic resonance spectroscopy," Plant Science, vol. 170, no. 6, pp. 1118-1124, 2006. 
[33] Y. S. Hong, A. Martinez, G. Liger-Belair, P. Jeandet, J. M. Nuzillard, and C. Cilindre, "Metabolomics reveals simultaneous influences of plant defence system and fungal growth in Botrytis cinerea-infected Vitis vinifera cv. Chardonnay berries," Journal of Experimental Botany, vol. 63, no. 16, pp. 5773-5785, 2012.

[34] R. Reggiani, M. Nebuloni, M. Mattana, and I. Brambilla, "Anaerobic accumulation of amino acids in rice roots: role of the glutamine synthetase/glutamate synthase cycle," Amino Acids, vol. 18, no. 3, pp. 207-217, 2000.

[35] A. Fait, H. Fromm, D. Walter, G. Galili, and A. R. Fernie, "Highway or byway: the metabolic role of the GABA shunt in plants," Trends in Plant Science, vol. 13, no. 1, pp. 14-19, 2008.

[36] Y. Miyashita and A. G. Good, "Contribution of the GABA shunt to hypoxia-induced alanine accumulation in roots of Arabidopsis thaliana," Plant and Cell Physiology, vol. 49, no. 1, pp. 92-102, 2008.

[37] S. D. McNeil, M. L. Nuccio, M. J. Ziemak, and A. D. Hanson, "Enhanced synthesis of choline and glycine betaine in transgenic tobacco plants that overexpress phosphoethanolamine $N$-methyltransferase," Proceedings of the National Academy of Sciences of the United States of America, vol. 98, no. 17, pp. 10001-10005, 2001.

[38] N. Benhamou and R. R. Bélanger, "Benzothiadiazole-mediated induced resistance to Fusarium oxysporum f. sp. radicis-lycopersici in tomato," Plant Physiology, vol. 118, no. 4, pp. 1203-1212, 1998.

[39] F. A. Rodrigues, N. Benhamou, L. E. Datnoff, J. B. Jones, and R. R. Bélanger, "Ultrastructural and cytochemical aspects of silicon-mediated rice blast resistance," Phytopathology, vol. 93, no. 5, pp. 535-546, 2003.

[40] T. P. T. Cushnie and A. J. Lamb, "Antimicrobial activity of flavonoids," International Journal of Antimicrobial Agents, vol. 26, no. 5, pp. 343-356, 2005.

[41] R. A. Dixon and N. L. Paiva, "Stress induced phenylpropanoid metabolism," Plant Cell, vol. 7, no. 7, pp. 1085-1097, 1995.

[42] S. Simoh, N. Quintana, H. K. Kim, Y. H. Choi, and R. Verpoorte, "Metabolic changes in Agrobacterium tumefaciens-infected Brassica rapa," Journal of Plant Physiology, vol. 166, no. 10, pp. 1005-1014, 2009.

[43] Y. Gao, M. Wang, X. Yang, Q. Sun, and J. Zhao, "Rapid detection of quinoline yellow in soft drinks using polypyrrole/single-walled carbon nanotubes composites modified glass carbon electrode," Journal of Electroanalytical Chemistry, vol. 735, pp. 84-89, 2014.

[44] S. Palanisamy, S. M. Chen, and R. Sarawathi, "A novel nonenzymatic hydrogen peroxide sensor based on reduced graphene oxide/ZnO composite modified electrode," Sensors and Actuators B: Chemical, vol. 166-167, pp. 372-377, 2012.

[45] J. V. Piovesan and A. Spinelli, "Determination of quercetin in a pharmaceutical sample by square-wave voltammetry using a poly(vinylpyrrolidone)-modified carbon-paste electrode," Journal of the Brazilian Chemical Society, vol. 25, no. 3, pp. 517-525, 2014.

[46] H. Zhu and G. Xu, "Electrochemical determination of ascorbic acid based on hydrothermal synthesized $\mathrm{ZnO}$ nanoparticles," International Journal of Electrochemical Science, vol. 12, pp. 3873-3882, 2017. 


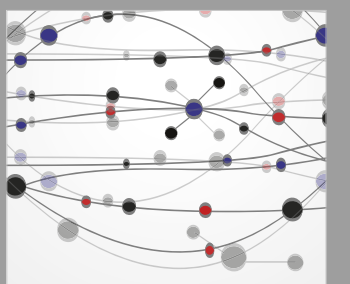

The Scientific World Journal
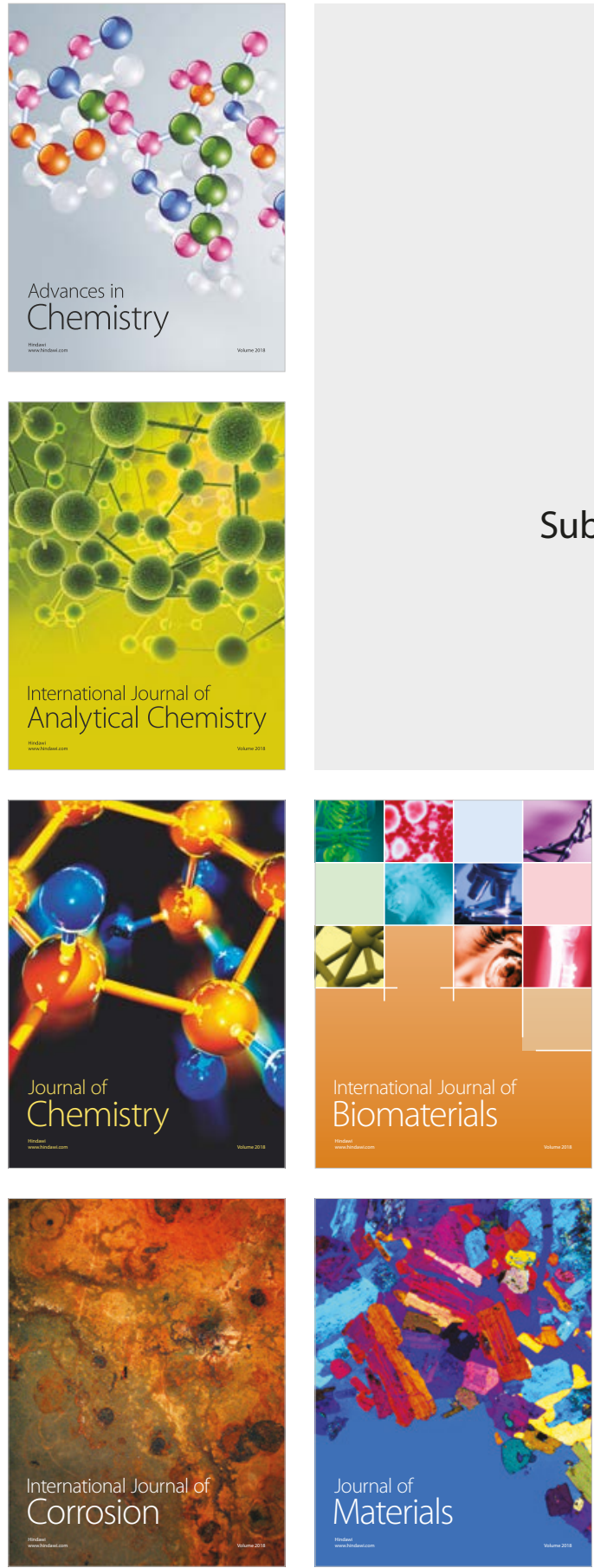

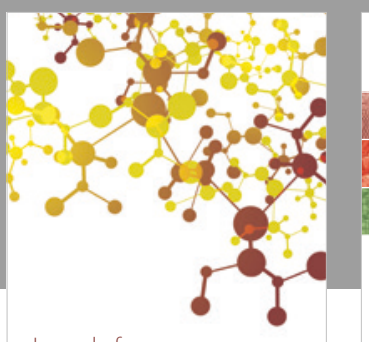

Journal of

Applied Chemistry
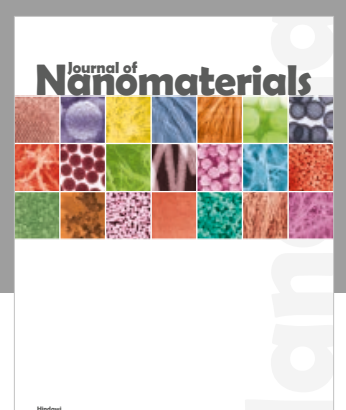

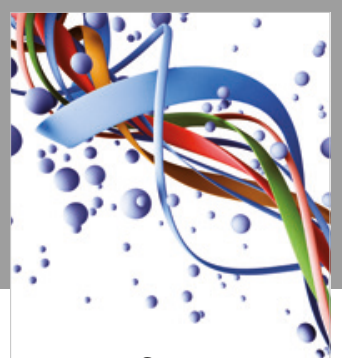

Scientifica

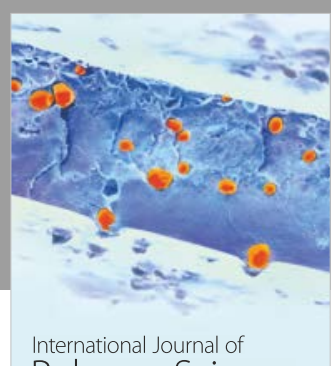

Polymer Science

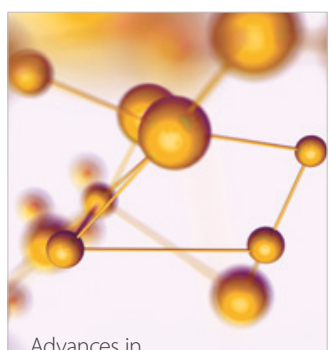

Physical Chemistry
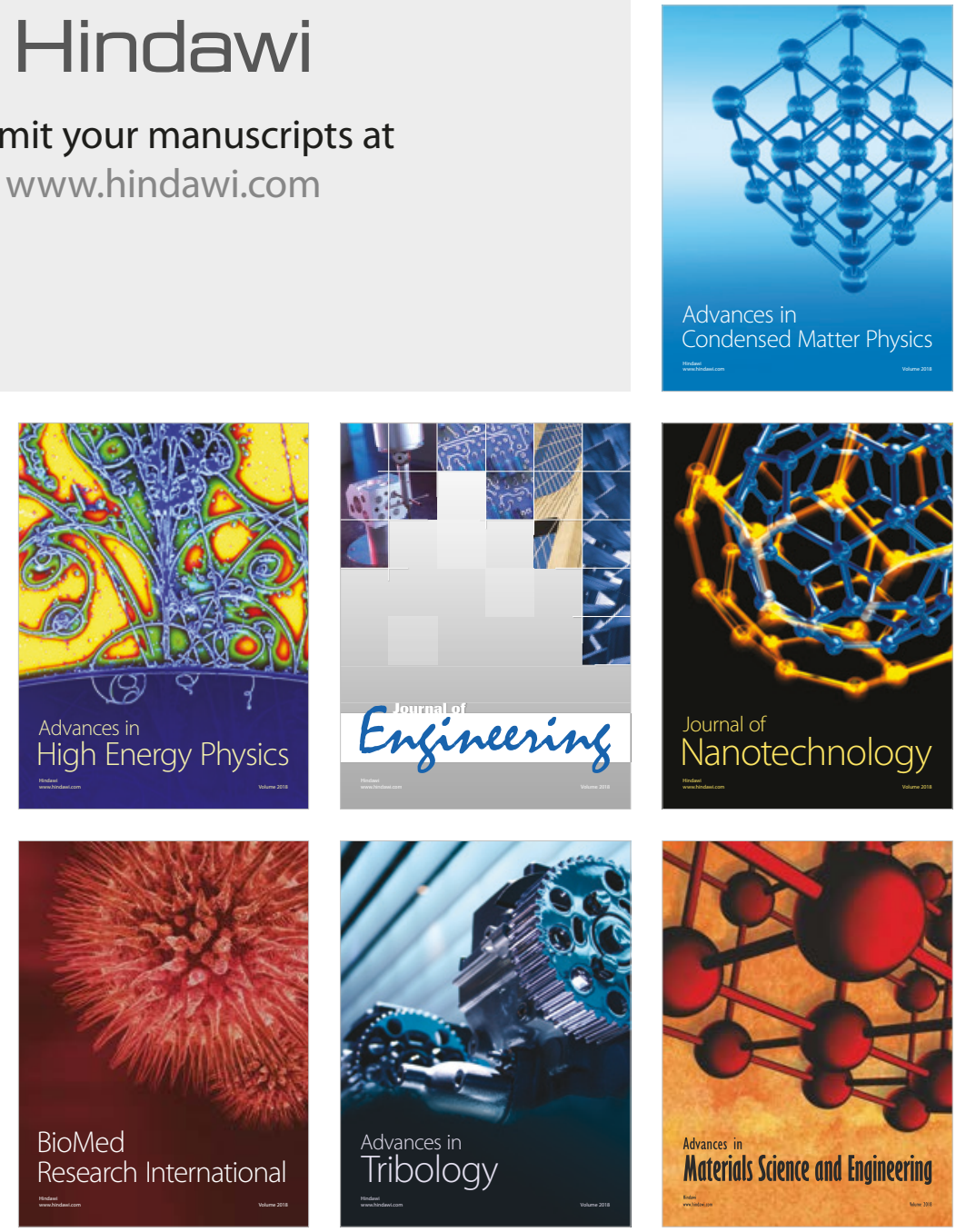